\title{
Agroecología, conocimiento tradicional e identidades locales para la sostenibilidad y contra el despoblamiento rural
}

\author{
Josep Espluga Trenc | Dpto. de Sociología, Universitat Autònoma de Barcelona \\ Daniel López García | Fundación Entretantos \\ Laura Calvet-Mir | Instituto de Gobierno y Políticas Públicas-Universitat Autònoma \\ de Barcelona \\ Marina Di Masso | Cátedra de Agroecología, Universitat de Vic-UCC \\ Ariadna Pomar León, Guillem Tendero Acin | Arran de Terra
}

URL de la contribución <www.iaph.es/revistaph/index.php/revistaph/article/view/4468>

\section{RESUMEN}

Una forma de superar algunas de las limitaciones de las políticas tradicionales de desarrollo rural es la apuesta por modelos agroalimentarios alternativos basados en la agroecología y la soberanía alimentaria. Los procesos de transición agroecológica pretenden, entre otras cosas, activar dos dinámicas fundamentales, la recuperación de conocimiento ecológico tradicional y la articulación de redes alimentarias alternativas, y para ponerse en marcha y mantenerse en el tiempo necesitan de un sistema organizativo en red que, en la medida de lo posible, cuente con el apoyo de las instituciones locales. En el caso español, en los últimos años cada vez más administraciones públicas están poniendo en marcha políticas alimentarias locales, con paradigmas relativamente distantes del modelo agroalimentario hegemónico. En el presente texto se analiza cómo los procesos de transición agroecológica pueden contribuir a activar y/o reinventar un patrimonio cultural que sea capaz de movilizar redes de actores en el territorio, y cómo estos procesos pueden modificar, a su vez, el funcionamiento de ciertas instituciones locales generando espacios participativos y foros híbridos de acción colectiva.

\section{Palabras clave}

Activismo ciudadano | Agroecología | Desarrollo rural | Identidades locales | Modelos agrarios | Patrimonio inmaterial | Políticas alimentarias | Recuperación de saberes | Soberanía alimentaria | 


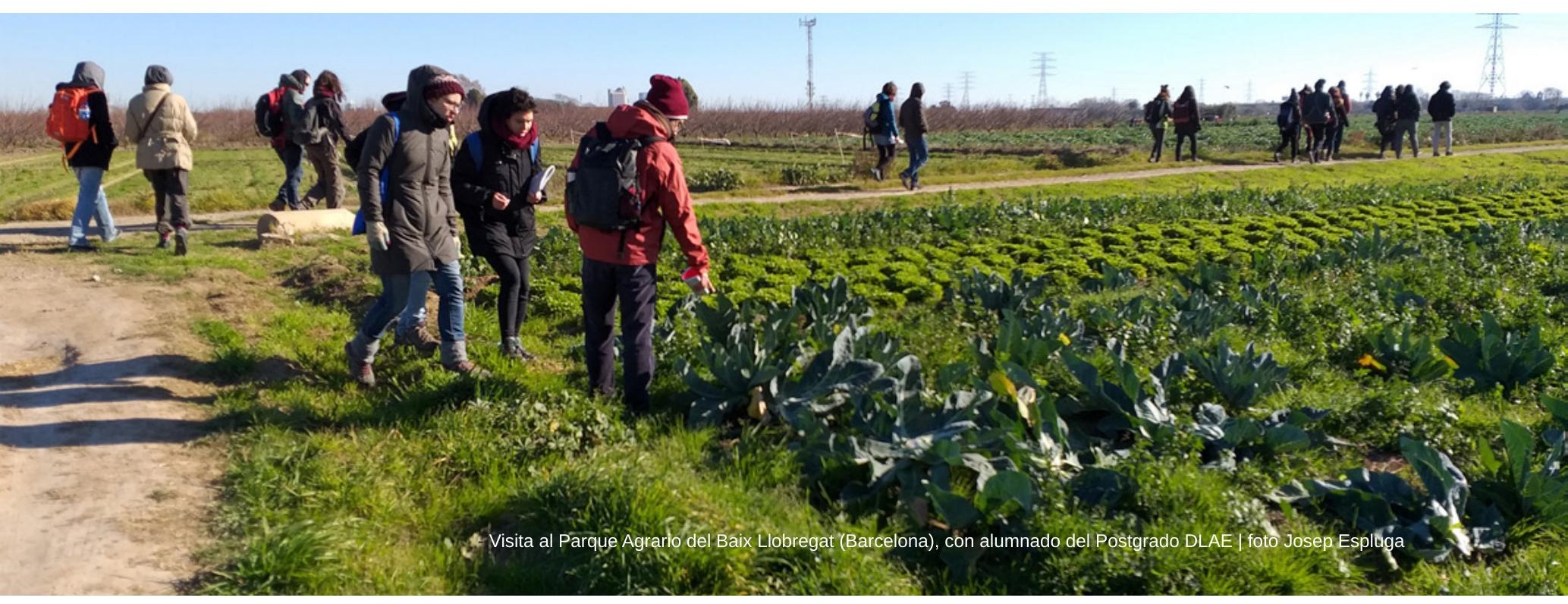

\section{Agroecology, traditional knowledge and local identities for sustainability and against rural depopulation}

\section{ABSTRACT}

One way to overcome some of the limitations of traditional rural development policies is the commitment to alternative agrofood models based on agroecology and food sovereignty. The agroecological transition processes intend, among other things, to activate two fundamental dimensions: the recovery of traditional ecological knowledge and the articulation of alternative food networks, and they need a networked organizational system supported, if possible, by local institutions. In the Spanish case, in recent years more and more public administrations have been implementing local food policies, with paradigms that are relatively distant from the hegemonic agro-food model. In the present text we analyzed how the processes of agroecological transition can contribute to activate and/or reinvent a cultural heritage capable of mobilizing actors' networks in the territory, and how these processes can modify, in turn, the functioning of certain local institutions introducing participative spaces and hybrid forums of collective action.

\section{Key words}

Citizen Activism | Agroecology | Rural Development | Local Identities | Agrarian Models | Intangible Heritage | Food Policies | Recovery of Traditional Knowledge | Food Sovereignty |

Cómo citar: ESPLUGA TRENC, J.; LÓPEZ GARCÍA, D.; CLAVET-MIR, L.; DI MASSO, M.; POMAD, A.; TENDERO, G. (2019) Agroecología, conocimiento tradicional e identidades locales para la sostenibilidad y contra el despoblamiento rural. Revista $P H$ [en línea], n. ${ }^{\circ}$ 98, octubre 2019, pp. 108-130 <www.iaph. es/revistaph/index.php/revistaph/article/view/4468>

Enviado: 03/07/2019 | Aceptado: 07/09/2019 | Publicado: 04/10/2019 


\section{LOS IMPACTOS TERRITORIALES DEL MODELO AGROINDUSTRIAL Y LA AGROECOLOGÍA COMO ALTERNATIVA}

Uno de los factores que más han influido en los cambios sociales en el mundo rural y, en particular, en la tendencia a la despoblación de buena parte del territorio, ha sido el modelo agrario hegemónico durante las últimas décadas. No obstante, la reivindicación de nuevos modelos agroalimentarios suele ser relegada a un segundo plano en los diagnósticos y propuestas para afrontar dicha problemática. Quizá sea debido a la dificultad de pensar en su modificación, dado el amplio apoyo con que cuenta desde numerosas instituciones públicas (gobiernos y administraciones públicas de diferentes niveles) y privadas (sector financiero, grandes corporaciones agroquímicas, grandes cadenas de distribución, etc.).

En este sentido, no es extraño que los programas de desarrollo rural hayan dedicado habitualmente la mayor parte de sus esfuerzos a intentar diversificar las actividades económicas en el territorio rural, dando por supuesto que el modelo agroindustrial es irreformable, o bien que su transformación escapa a las posibilidades de las instituciones y entidades implicadas.

Sin negar que la búsqueda de actividades alternativas a la agricultura sea algo muy loable, aquí se pretende desarrollar la idea de que una de las principales bazas del mundo rural pasa por considerar la tierra y las actividades relacionadas con el sistema agroalimentario local como algo esencial para el presente y el futuro de muchos territorios (aunque quizá no de todos). Y que, para ello, se requiere de modelos agrarios alternativos como los propuestos por la agroecología.

La crisis ambiental y socioeconómica de la agricultura industrializada a escala global ha comportado la aparición de la agroecología como un enfoque teórico y metodológico que tiene como objetivo aumentar la sustentabilidad agraria desde una perspectiva ecológica, social y económica (FRANCIS; LIEBLEIN; GLIESSMAN et ál., 2003). En este sentido, la agroecología podría definirse como un enfoque teórico y metodológico que persigue el incremento de la sustentabilidad agraria, integrando para ello a disciplinas de las ciencias naturales (ecología, agronomía, ciencias veterinarias, etc.) y sociales (sociología, historia, antropología, etc.). No obstante, existe una cierta diversidad respecto al alcance de esta integración metodológica, pues mientras hay quienes consideran la agroecología como la ciencia que aplica los conceptos y principios ecológicos al diseño y manejo de agroecosistemas sustentables (GLIESSMAN, 1997), hay quienes la conciben como la forma de analizar todo tipo de procesos agrarios en sentido amplio, de tal forma que los ciclos minerales, las transformaciones de la energía, los procesos biológicos y las relaciones socioeconómicas sean investigadas y analizadas como un todo (ALTIERI, 1987). 
En definitiva, desde el punto de vista de la agroecología no sólo se tiene en cuenta cómo se ha producido un alimento (con técnicas ecológicas, sostenibles, etc.), sino también qué relaciones de producción han permitido producirlo. Es decir, las relaciones existentes entre las diferentes personas y posiciones que participan en el sistema agroalimentario, lo que permite introducir criterios de justicia, equidad, etc., en la valoración de dicho sistema.

Desde nuestro punto de vista, para poder ser útil en la resolución de los problemas asociados a la expansión del modelo agroindustrial, como los impactos socioeconómicos y territoriales por disminución de la población activa agraria y los correlativos éxodos rurales, empobrecimiento y superpoblación de las áreas urbanas, e incluso impactos políticos y geopolíticos por la acusada redistribución del poder en favor de grandes productores, terratenientes y corporaciones empresariales globales, la agroecología debería concebirse en un marco político de soberanía alimentaria. De manera genérica, la soberanía alimentaria implicaría el derecho de las personas, comunidades, pueblos y países a definir sus propias políticas agrícolas, laborales, pesqueras, alimentarias y de tierra de forma que sean ecológica, social, económica y culturalmente apropiadas a sus circunstancias únicas (SOBERANÍA, 1996). Este concepto incluiría el derecho a la alimentación, garantizado con el correlativo derecho a la producción de alimentos, constituyendo así una apuesta clara por el mantenimiento y promoción de la agricultura como eje central del desarrollo territorial.

Cada vez más iniciativas locales comparten estas orientaciones a lo largo del mundo. En el caso español, aunque en un principio fueron promovidas principalmente por movimientos sociales e iniciativas particulares, desde hace unos años (y con claridad a lo largo del penúltimo ciclo electoral municipal de 2015-2019) los gobiernos locales están apostando cada vez más por políticas alimentarias locales. Es decir, en los últimos años gobiernos y administraciones locales, como ayuntamientos, consejos comarcales, diputaciones, consorcios territoriales y otras entidades de carácter local supramunicipal, tienden a promover, tímidamente, políticas agroecológicas y con perspectiva de soberanía alimentaria.

Probablemente, la iniciativa más importante de la que tenemos constancia por su dimensión y alcance fue la creación de la Dirección General de Agricultura Ecológica en Andalucía (2004-2007), única hasta el momento, que desarrolló innumerables programas con enfoque agroecológico, incluyendo los Planes de Agricultura Ecológica de las comarcas de Alpujarras y Vega de Granada, o el mayor programa de compra pública alimentaria desarrollado hasta el momento en el Estado español, incluyendo 150 centros educativos y 2 hospitales abastecidos directamente por una red de más de 70 fincas y cooperativas de producción familiar ecológica (GONZÁLEZ 
Agricultura periurbana. Parque agrario del Baix Llobregat (Barcelona) | foto Josep Espluga

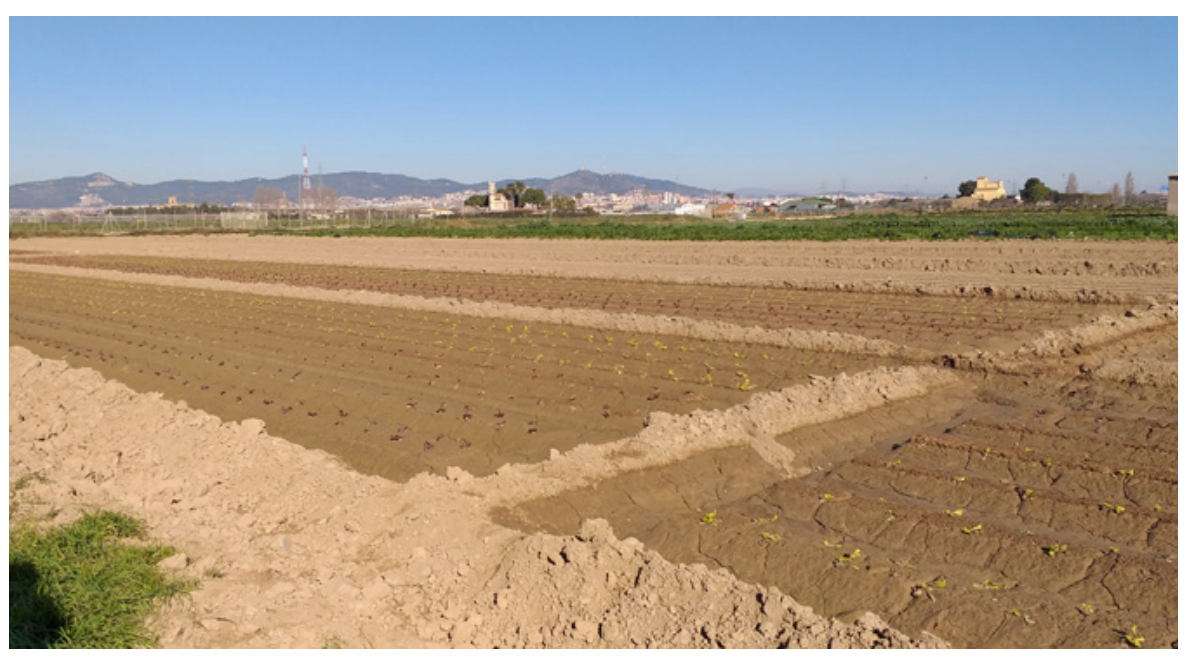

DE MOLINA, 2009). Más recientemente (2014-2016), la Dirección General de Comercio de la Junta de Andalucía puso en marcha el proyecto de Territorialización del Comercio en Andalucía, que incluyó procesos participativos en 18 comarcas para articular en las escalas locales a pequeño comercio, producción agraria y otros actores locales (no vinculados directamente con el sistema agroalimentario). Ambos proyectos tuvieron un final abrupto motivado por cambios políticos ligados a los ciclos electorales $y$, a pesar de que muchos procesos y proyectos actualmente en marcha beben de estos orígenes, resulta difícil evaluar su impacto sobre el desarrollo rural y el despoblamiento en Andalucía debido a su falta de continuidad.

En otros territorios, diversas administraciones están trabajando con un enfoque multi-nivel, por el desarrollo de procesos de transición agroecológica en el medio rural. Podríamos citar, entre otros, los tres grupos operativos puestos en marcha a partir de 2016 por el Instituto Madrileño de Investigación Agraria (IMIDRA), junto con la administración autonómica, distintas administraciones locales, Grupos de Acción Local, organizaciones de productores/ as ecológicos/as y entidades sociales.

También el proyecto Municipis en Saó lanzado en 2018 por la Federación Valenciana de Municipios y Provincias y la ONG CERAI, orientado a formar, asesorar y acompañar a pequeños municipios en el desarrollo de políticas alimentarias con enfoque agroecológico. O el proyecto BCN Smart Rural lanzado en 2018 por la Diputación de Barcelona junto con l'Associació d'Iniciatives Rurals de Catalunya (ARCA) y el Centre de Ciència i Tecnologia Forestal de Catalunya (CTFC), que incluye la puesta en marcha de bancos de tierras, incubadoras agroecológicas, u otras actuaciones con perspectiva agroecológica. Esta última iniciativa coincide y se refuerza con la creación de la Xarxa de Municipis per la Sobirania Alimentària de Catalunya Central, en 


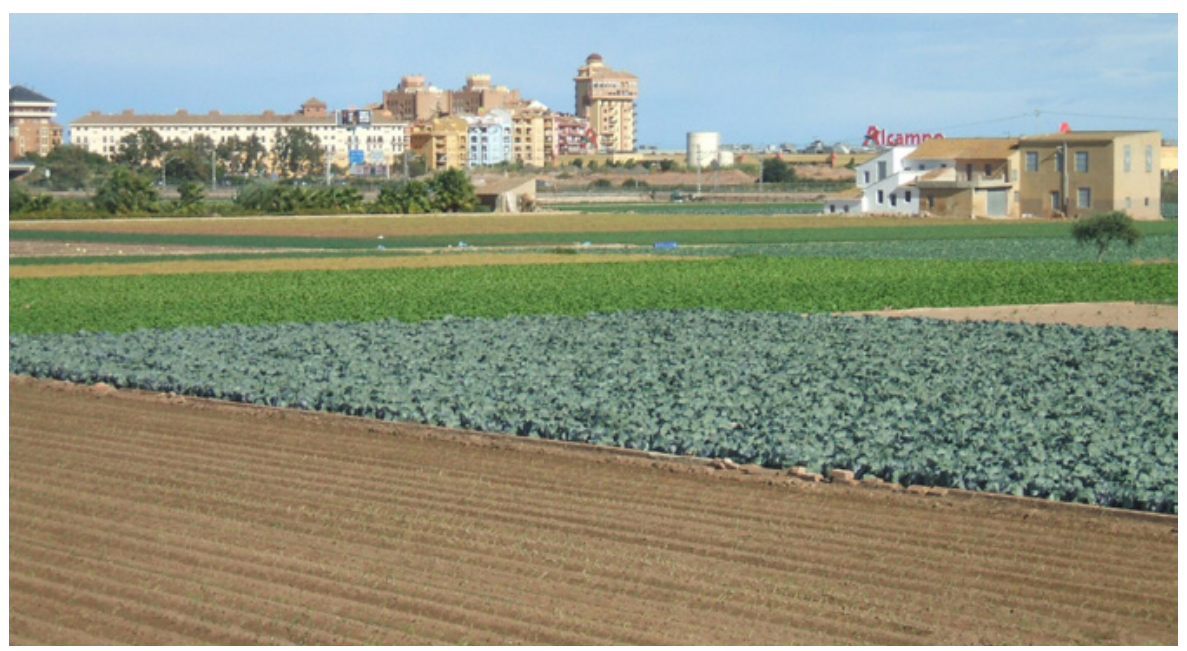

constitución en 2019. El reciente desarrollo de todos estos proyectos impide, en todo caso, poder evaluar su impacto sobre la despoblación en las comarcas rurales.

Pero quizá, el proceso que más ha avanzado, y del que se podrían constatar resultados, sería el impulsado por el sindicato agrario EHNE-Bizkaia (muy vinculado a La Vía Campesina) desde principios de siglo, para la incorporación de jóvenes a la actividad agraria desde un enfoque agroecológico y de soberanía alimentaria. A partir de acciones de formación y acompañamiento a la instalación de jóvenes en la actividad agraria, se crea en 2005 la red de grupos de consumo de alimentos ecológicos Nekasarea, que llegaría a articular a 60 grupos de consumo y más de 80 productores/as, en un esquema de Agricultura Sostenida por la Comunidad. A partir de esta estructura, desde el sindicato y otros actores de Euskal Herria (como la organización Etxalde, la Fundación Emaús o el Instituto HEGOA de la UPV) se impulsaría un proceso de creación de estructuras y redes económicas con enfoque agroecológico (por ejemplo, EH Kolektiboa) y fortalecimiento y articulación de otras ya existentes (como Biolur y Ekonekazaritza desde la producción ecológica). Se trata de un proceso de incidencia política que ha logrado la implicación de numerosos ayuntamientos en la promoción de transiciones agroecológicas locales, tales como Zeberio, Orduña, Larrabetxu y otros. Fruto de este proceso multi-actor y multi-nivel, impulsado por un sector productor comprometido con la agroecología, se ha podido observar un refuerzo de las producciones familiares ecológicas, de organizaciones agroecológicas, de creación de empleo agrario y agroalimentario, y en general de las dinámicas socio-económicas en algunos territorios rurales de Bizkaia especialmente, pero también de Gipuzkoa (Azpeitia, Hernani), y en menor medida Nafarroa (Baztán, Estella-Lizarra, Pamplona-Iruña) y Araba (Vitoria-Gasteiz).
Agricultura periurbana en Alboraia (Valencia) | foto Daniel López. 
Todos estos procesos se caracterizan por una serie de propuestas prácticas más o menos similares. A partir de un análisis de las políticas alimentarias locales de diversos municipios catalanes (Barcelona, Canet de Mar, Cardedeu, Granollers, Lleida, Manresa, Navàs, El Prat de Llobregat, Sabadell, Sant Cugat del Vallès, Vic, Vilanova i la Geltrú) (ESPLUGA; DI MASSO; LÓPEZ GARCÍA, 2019), se concluyó que compartían los siguientes rasgos:

a) El apoyo a la producción ecológica: en forma de apoyo y formación para las personas productoras; de sensibilización a consumidoras; de creación de marcas locales de calidad, etc.

b) La recuperación del conocimiento ecológico tradicional y de recursos locales: en forma de bancos de semillas; de ferias de variedades locales; de promoción de asociaciones de productores de semillas y variedades locales; de convenios con sectores de la restauración local para promover su consumo; de bancos de tierras para ponerlas a disposición del campesinado local (a menudo con tierras de propiedad pública, ante la dificultad de conseguir tierras privadas, de algún modo secuestradas por ciertos efectos perversos de la Política Agrícola Común, PAC); de iniciativas de custodia territorial que ponen en contacto a propietarios de la tierra y productores agroecológicos, etc.

c) La promoción de redes alimentarias alternativas: con apoyo a la venta directa en finca, a domicilio o en grupos de consumo; en mercados locales; el fomento de cooperativas de consumo; de cooperativas conjuntas de productores y consumidores ecológicos; de puntos de venta colectivos de productores ecológicos organizados; de alianzas entre productores y restauradores; de apoyo a tiendas especializadas en producto local, de espacios colectivos de acopio, de compra pública agroecológica (en comedores escolares, hospitales, residencias, etc.).

d) La promoción de huertos urbanos, sociales y/o comunitarios: unos espacios que, más allá del autoconsumo que puedan procurar, aportan relevantes funciones de ocio, de inclusión social, de empoderamiento social y colectivo, de contacto con la naturaleza, etc., y que constituyen una política pública clave para la recuperación de entornos degradados desde el punto social y urbanístico (MARULL; DOMENE; GARCÍA et ál., 2016).

e) La constitución de organismos de gestión: la aplicación de todas las políticas anteriores requiere de una estructura organizativa en forma de consejo alimentario municipal o de unidades administrativas encargadas de diseñar estrategias alimentarias municipales (o territoriales), normalmente con mecanismos participativos que permitan integrar a los diversos actores del sistema agroalimentario local. 
En algunos casos más recientes, si bien mayormente urbanos, el desarrollo de políticas alimentarias locales está tratando de acercarse a la esfera de los cuidados, a través del diálogo con la economía feminista y sus aplicaciones prácticas (CLEMENTE; LÓPEZ-GARCÍA; DIMASSO et ál., 2012). En este sentido, ciudades como Córdoba están vinculando sus servicios de atención a la emergencia alimentaria con las redes de producción ecológica que el propio Ayuntamiento dinamiza, en torno al proyecto "Alimentando Córdoba". Y ciudades como Zaragoza y Valencia han incluído en sus respectivas Estrategias Alimentarias la perspectiva de igualdad de género, de forma explícita (ESTRATEGIA, 2019).

A continuación, nos centraremos en el análisis de la capacidad o potencialidad de algunas de estas iniciativas para dinamizar el patrimonio cultural local.

\section{LA AGROECOLOGÍA Y LA RECUPERACIÓN DE SABERES LOCALES}

La agroecología parte del supuesto de que cada territorio tiene unas características agroecosistémicas y socioculturales particulares, que el modelo agroalimentario a desarrollar en dicho territorio debería tener en cuenta. A diferencia del modelo agroindustrial, que permite cultivar variedades estandarizadas gracias al uso intensivo e indiscriminado de insumos químicos, energía y tecnología, la agroecología procura la recuperación de variedades locales culturalmente adaptadas al lugar en cuestión, así como de unas prácticas de cultivo tradicionales, sin renunciar a las innovaciones tecnológicas que se puedan incorporar.

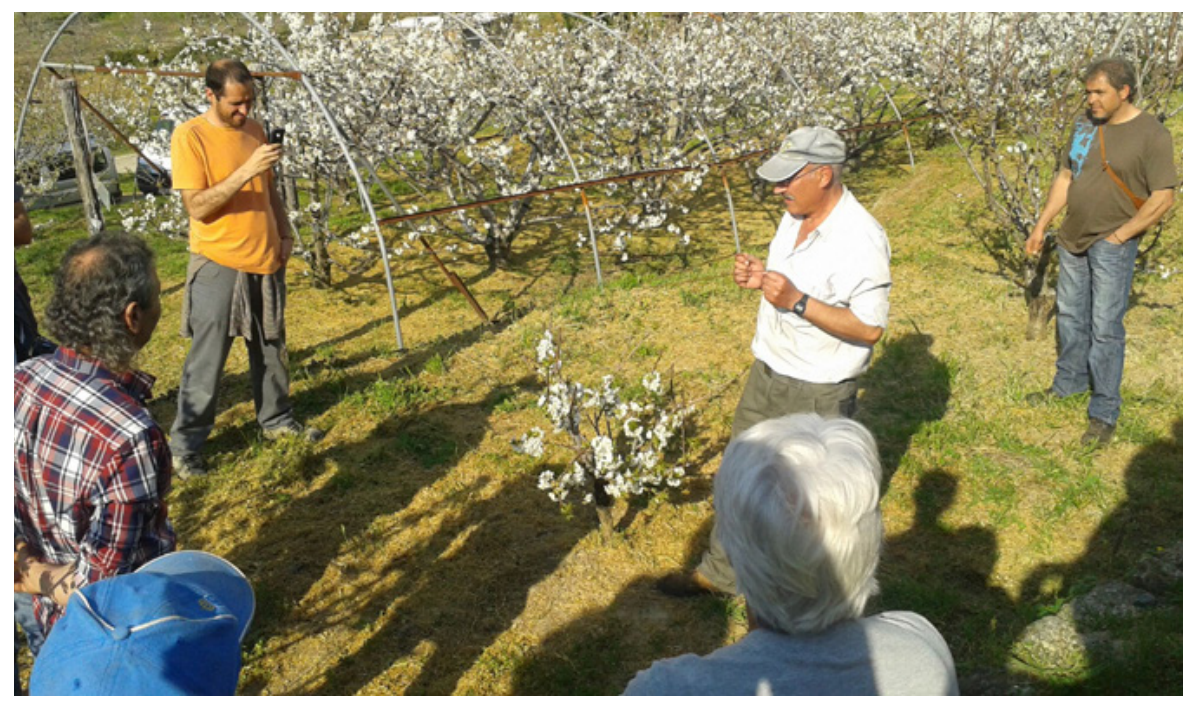

Agricultores ecológicos comparten conocimientos sobre cultivo de cerezos (Cáceres) | foto Daniel López 


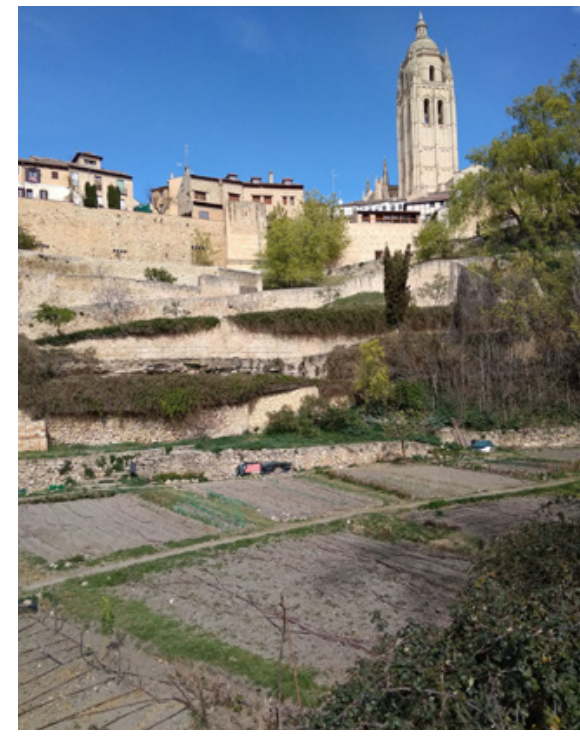

Huertos de ocio en Segovia | foto Daniel López
El conocimiento ecológico tradicional (CET) es un cuerpo acumulativo de conocimiento, creencias, tradiciones, prácticas, instituciones y cosmovisiones que ha evolucionado mediante procesos adaptativos y se ha transmitido de generación en generación a través de la transmisión cultural (CALVETMIR, 2019). Este cuerpo de conocimiento contiene información sobre las relaciones entre los seres vivos (incluyendo los seres humanos) entre sí y con su medio ambiente (BERKES, 2004), y está basado en información que proviene de la experiencia de un cierto grupo cultural acumulada de generación en generación, compartida socialmente por la comunidad y los hogares, y que es particular de cada individuo (TOLEDO, 2002). El mantenimiento del CET requiere de una interacción continua de las comunidades con los ecosistemas de los cuales forman parte y unas redes sociales y marcos institucionales fuertes y bien conectados. Como puede observarse, el mantenimiento del CET puede constituir un factor clave para el mantenimiento de los vínculos sociales a nivel local, así como contribuir a generar rasgos culturales, es decir, conocimientos y símbolos compartidos por la comunidad.

Gómez-Baggethun y Reyes-García (2013) y Reyes-García (2015) sugieren que el CET tiene una naturaleza híbrida y dinámica capaz de adaptarse a los cambios ecológicos y socioeconómicos. Según estos autores, dicha adaptación se consigue mediante el establecimiento de nuevas formas de conocimiento y/o desechando los componentes del CET que se vuelven obsoletos o menos útiles para la vida diaria. La mezcla entre diferentes cuerpos de conocimiento (científico y tradicional) y la naturaleza adaptativa del CET se han documentado en casos donde el uso de nuevas tecnologías ha ido de la mano de prácticas secularmente utilizadas en la gestión de agroecosistemas. Por ejemplo, Calvet-Mir (2019) reporta un estudio en la Vall de Gósol (Pirineo catalán), donde constata que debido al aumento en la temperatura local, los hortelanos se dieron cuenta que el guisante negro (Pisum sativum L.), una variedad local muy apreciada en la zona, se veía afectada por el gorgojo del guisante (Bruchus pisorum), una plaga que no había sido documentada en la zona anteriormente. Para proteger a los guisantes negros del gorgojo una vez recolectados, se observa que los hortelanos los almacenan en el congelador durante tres días para evitar la proliferación de dicha plaga (RIUBOSOMS, 2012). En los huertos del noroeste de la Patagonia, Eyssartier, Ladio, y Lozada (2011) observaron que los hortelanos mantenían el conocimiento y las prácticas tradicionales a la hora de gestionar los huertos familiares, pero que también utilizaban invernaderos modernos para mejorar las condiciones de ciertos cultivos. En un estudio reciente con hortelanos españoles, Reyes-García, Aceituno-Mata, Calvet-Mir et ál. (2014) constataron que el mantenimiento del CET se combinaba con la adopción de prácticas y tecnologías modernas, siendo los hortelanos con mayor CET los que también tenían más conocimiento sobre prácticas y tecnologías modernas. Todos estos estudios sugieren que el CET está en un continuo proceso de adaptación a las nuevas situaciones bióticas y a los cambios socioeconómicos. 
En este mismo sentido, Gómez-Baggethun, Mingorría, Reyes-García et ál. (2010) analizaron la transmisión de conocimiento ecológico tradicional entre habitantes locales en comunidades vinculadas con espacios protegidos en Doñana (Andalucía). Se estudiaron los cambios en el conocimiento relacionado con prácticas tradicionales de agricultura y ganadería entre 198 informantes de tres generaciones distintas, que cubrían el período en que Doñana pasó de tener una economía fuertemente dependiente de sus recursos naturales a una economía de mercado con sistemas de producción intensiva. Ello comportó una pérdida abrupta del CET relacionado con la agricultura, debido a las rápidas transformaciones y a la intensificación de los sistemas agrícolas (básicamente la conversión de humedales en campos de arroz y fresas altamente mecanizados y muy dependientes de insumos externos). No obstante, el CET referente a la ganadería se conservó mejor, probablemente por tratarse de una actividad permitida en los espacios protegidos de Doñana, y porque ha mantenido fuertes vínculos con la identidad cultural local, como la conocida Saca de yeguas, una feria de ganado anual de una semana de duración. Los resultados muestran el potencial de los espacios protegidos para mantener los remanentes de CET en países desarrollados. Sin embargo, los autores señalan también que la protección ambiental estricta del territorio puede interrumpir los largos procesos de almacenamiento y transmisión de CET, ya que los usuarios de los recursos locales y las prácticas relacionadas suelen ser excluidos del manejo del ecosistema.

En este sentido, Reyes-García (2009) explica que el CET ha sido clave, por ejemplo, en el mantenimiento de las dehesas españolas, un agroecosistema productivo considerado como una solución exitosa entre producción y conservación biológica, donde se combina la producción simultánea de ganado (cerdo ibérico, ganado ovino, ganado vacuno), caza menor y mayor, leña, carbón y eventualmente corcho. La gestión de uso múltiple de las dehesas (integrando ganadería, agricultura y silvicultura) configura un paisaje vegetal característico, compuesto fundamentalmente por dos estratos vegetales: pasto herbáceo de especies anuales y arbolado (encina, quejigo, alcornoque y ocasionalmente melojo). La autora subraya también que la intensificación y/o el abandono de las dehesas durante las últimas décadas pueden tener consecuencias imprevistas para la biodiversidad y erosionar el CET que las sustenta.

En definitiva, existe un cierto acuerdo en considerar que el CET favorece la conservación ecológica y de la biodiversidad en general a través de un diálogo de saberes con los científicos de la conservación (MOLLER; BERKES; LYVER et ál., 2004), permitiendo la reproducción de las especies a través de sistemas periódicos de cierre de los ecosistemas (CINNER; MARNANE; MCCLANAHAN et ál., 2005) o reduciendo la presión de la caza a través de tabús (PURI, 2005). No obstante, también existen estudios que han documentado casos de explotación no sostenible de los recursos naturales por 

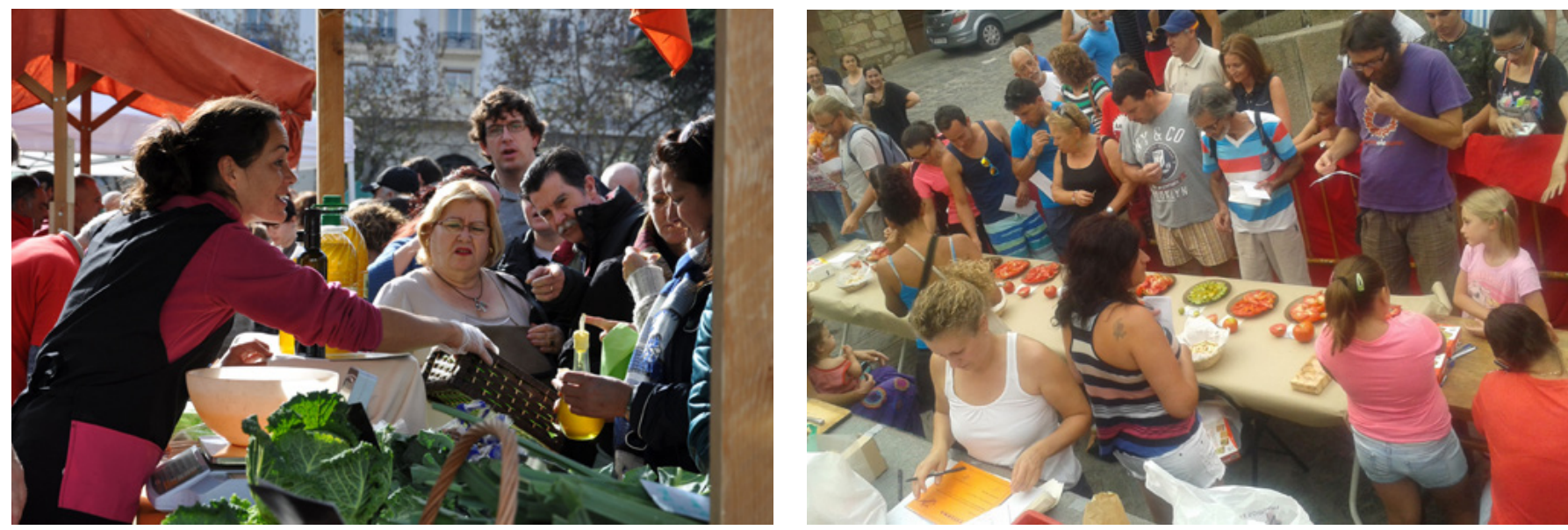

A la izquierda, feria de l'Horta a la Plaça, Valencia a la derecha, concurso de variedades de tomate cultivadas en Garganta la Olla (Cáceres) | foto Daniel López

parte de la población local debido a presiones exteriores o al incremento de la densidad poblacional, que finalmente han conducido a la destrucción de hábitats y/o al colapso de dichas sociedades (HENRICH, 2004; DIAMOND, 2005). Por otro lado, hay quienes también han cuestionado el valor del CET para la gestión de los recursos naturales sin una consciencia ambiental previa (SMITH; WISHNIE, 2000). Sin embargo, la mayoría comparte la idea de que el CET incrementa la capacidad de los sistemas socio-ecológicos de hacer frente a crisis y perturbaciones, para mantener la capacidad de recuperación a largo plazo y, por lo tanto, responder al cambio ambiental global o aumentar su resiliencia.

Dentro de la transición agroecológica, el conocimiento tradicional campesino y sus producciones materiales (variedades locales, herramientas, infraestructuras) juegan un papel central a través de su propia materialidad, que logra reconfigurar el espacio simbólico en el que se reproduce la sociedad agraria, mostrando así un fuerte carácter performativo de la realidad (DIRKSMEIER; HELBRECHT 2008; DANIEL, 2011). En este sentido, el conocimiento tradicional campesino logra articular componentes tanto simbólicos como materiales de la ruralidad (BELL; LLOYD; VAVOTEC, 2010). De algún modo, la idea de ruralidad mantiene todavía la capacidad de generar símbolos y referentes capaces de comercializar los nuevos productos "tradicionales", de generar procesos de contra-urbanización, o de movilizar alianzas urbanas en defensa de ciertos paisajes rurales o de ciertos alimentos locales (REED, 2008; LÓPEZ, 2011).

Las ferias de variedades locales permiten visualizar estas tradiciones y su puesta en valor. En el caso de Morata de Tajuña (LÓPEZ GARCÍA; GUZMÁN CASADO, 2013), la organización de una feria de este tipo permitió identificar y presentar las variedades tradicionales locales como realidades de hecho, a pesar de que su existencia había sido negada por técnicos de la admi- 


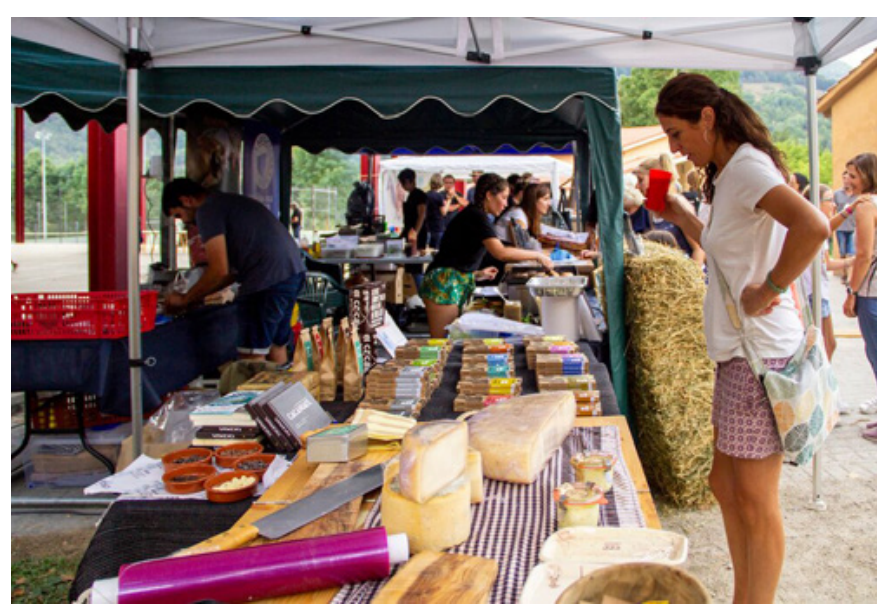

nistración agraria local y por varios agricultores. Hacer visible la existencia de estas realidades alternativas a los modelos hegemónicos de modernización agraria posibilita plantear caminos diferentes o complementarios a dicha modernización (en este caso las ubicuas semillas mejoradas), ya que si aquellas semillas se mantuvieron es porque tenían algún valor para aquella comunidad, sea el que sea. Mostrar esta realidad alternativa amplía las opciones de futuro posibles para el sector agrario local.

Hay acuerdo también en que la erosión y el cercado (apropiación, patentes, privatización, etc.) de los CET amenazan su uso y reproducción, lo que a su vez podría afectar su contribución potencial a las transiciones agroecológicas. Calvet-Mir, Benyei, Aceituno-Mata et ál. (2018) han explorado en qué medida la conversión del CET sobre variedades locales en una propiedad digital puede contribuir a su mantenimiento y protección. Para ello han analizado el funcionamiento de la plataforma CONECT-e, una iniciativa para almacenar y compartir digitalmente CET de manera participativa. Un año después de su lanzamiento, CONECT-e había documentado 452 variedades locales de 81 especies diferentes. La información compartida en esta plataforma en línea permite estructurar la información de manera clara y fiable, así como la replicación del conocimiento reportado para quien esté interesado en ello. Además, dado que CONECT-e hace que la información documentada esté disponible de forma gratuita y protegida con una licencia de copyleft, colocar información en esta plataforma podría ayudar a afrontar los problemas de apropiación indebida recurrentes en este campo (biopiratería), al quedar incluida en el marco de los bienes comunes digitales.

En definitiva, la agroecología permite la recuperación de un patrimonio material e inmaterial, las variedades locales, su manejo y su uso, de una manera dinámica e integrada en proyectos de vida locales, contribuyendo a la viabilidad de procesos de transición agroecológica de dimensión territorial. 


\section{LA AGROECOLOGÍA Y EL FORTALECIMIENTO DE IDENTIDADES LOCALES}

Uno de los principales impactos del sistema agroalimentario hegemónico ha sido la intensa redefinición de las identidades agrarias, disociándolas de las culturas locales, lo cual ha tenido a su vez efectos en la reconfiguración de los vínculos de la población en general con su territorio. Desde una perspectiva personal y simbólica, "el sistema agroalimentario engulle a los agricultores reduciéndolos en su importancia, y su función tiende más hacia la producción de materias primas agrarias que hacia la producción de alimentos. El trabajo de agricultor también cambia radicalmente, pasando a tener como leitmotiv la gestión empresarial de la explotación, más que mantener la agricultura entendida como una forma de vida" (GALLAR, 2011: 34). Las políticas públicas de apoyo a la modernización han venido de la mano de una importante "ofensiva cultural", en la cual la industrialización se ha manifestado como una "victoria" de los agricultores profesionales (aquellos con explotaciones fuertemente especializadas, capitalizadas y tecnificadas), que pasaron a ser los únicos agricultores considerados verdaderos: "se concibe el futuro como una mercancía escasa, y pocos sobrevivirán" (PLOEG, 2010: 206). La actividad agraria se convierte así en una actividad alienante que reduce la autoestima del agricultor (SÁNCHEZ DE PUERTA; TABERNER, 1995) para construir una nueva identidad empresarial, individualizada y disociada de la cultura y el territorio locales.

Durante las últimas décadas los agricultores han construido sus identidades sociales y profesionales de acuerdo con un reducido conjunto de prácticas agrarias (o estilos) dominantes, donde los conceptos de productividad, innovación y eficiencia han sido valores importantes (ESPLUGA, 2002; 2004). Lockie (1997) ya advertía que no se puede ignorar el hecho de que la agrociencia está plenamente incorporada a los conocimientos locales de los agricultores que habían sobrevivido a la revolución verde. Es decir, hay que tener en cuenta que, al menos durante el último medio siglo, ha habido una gran afinidad entre agricultores y agroindustria, y que dicha asociación juega una gran centralidad en la construcción de la identidad social de los agricultores como profesionales eficientes e innovadores de la tierra. Además, en un estudio pionero sobre la percepción ambiental de los agricultores españoles, Garrido (1999) ya describía la paradójica situación donde el agricultor aparecía como contaminador y como víctima al mismo tiempo, ya que mientras por un lado se le incitaba a producir al máximo, por otro lado se le exigía actuar cada vez con mayor respeto medioambiental, cosa que ellos mismos percibían como incompatible con las prácticas agrícolas dominantes.

La agroecología ofrece vías de salida a dichas contradicciones, por la vía de la reducción de dependencias respecto al sistema agroindustrial, el empoderamiento personal y profesional y la generación de complicidades con el 


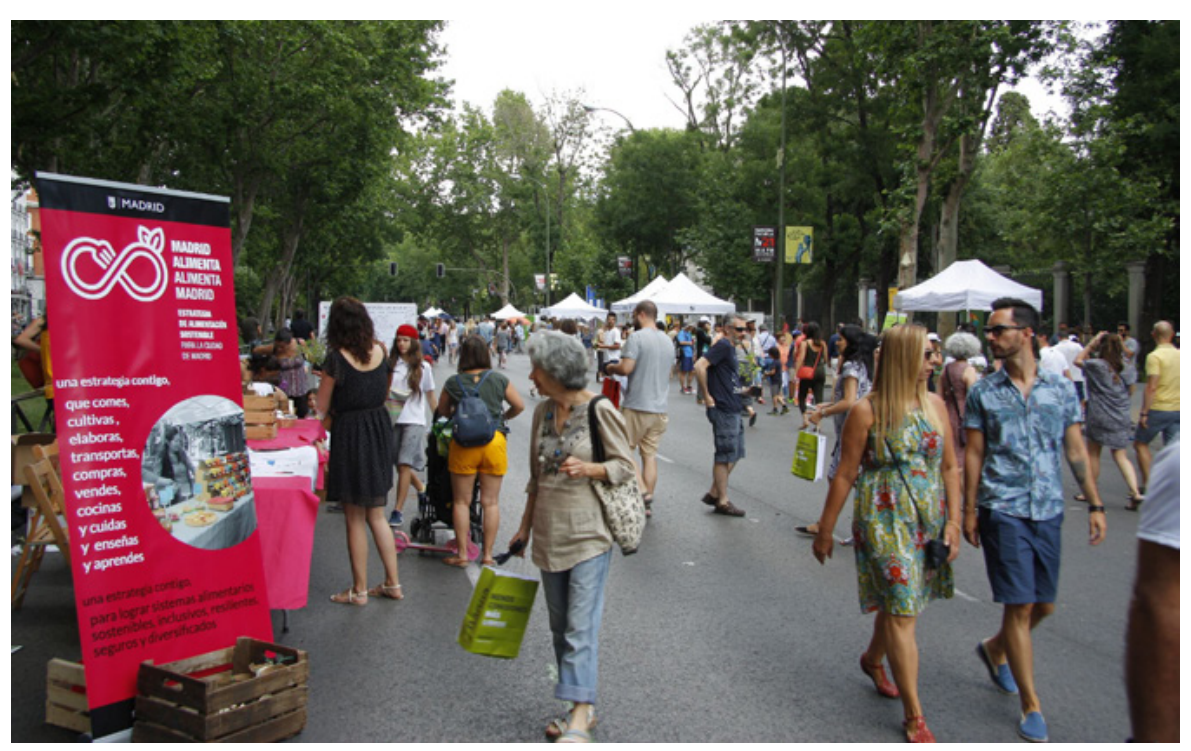

Día de la Alimentación, Paseo del Prado (Madrid) | foto Daniel López

sistema social local. Por ejemplo, en una prospección de CET realizada en Morata de Tajuña, López García y Guzmán Casado (2013) encontraron poco material genético local (sólo algunas variedades de árboles frutales), pero en cambio obtuvieron información de gran interés acerca de formas de manejo tradicionales, con un gran potencial para reinventar las prácticas agrarias sostenibles -social y ecológicamente- en el municipio. A la hora de plantear la transición agroecológica local, la visibilización de dichas prácticas tuvieron un enorme potencial performativo sobre el imaginario colectivo local y supusieron una herramienta valiosa para construir el entorno simbólico, necesario para la emergencia de alternativas al modelo agroindustrial hegemónico.

La reconstrucción de la sociabilidad en torno al patrimonio agrario local permite situar la coevolución sociedad-ecosistema en el centro de la identidad local. En este sentido, los espacios de cooperación en base a bienes comunes como el paisaje, el conocimiento ecológico tradicional o las semillas autóctonas, por ejemplo, permiten emerger las identidades colectivas -el nosotrosalrededor de las características del territorio, no sólo entre los agricultores sino también entre otros actores que forman parte del sistema agroalimentario local (personas comerciantes, restauradoras, transformadoras, consumidoras, etc.).

En este sentido, el patrimonio agrario campesino ha mostrado que puede ser motor de la economía local, como en el caso de las rutas gastronómicas y las alianzas con el sector de la restauración. El proceso de desagrarización de las últimas décadas ha alejado a la población del patrimonio agrario local, incluso en el mundo rural. Sin embargo, los sectores hosteleros locales, por ejemplo, pueden reconstruir una visión innovadora de la identidad local a 


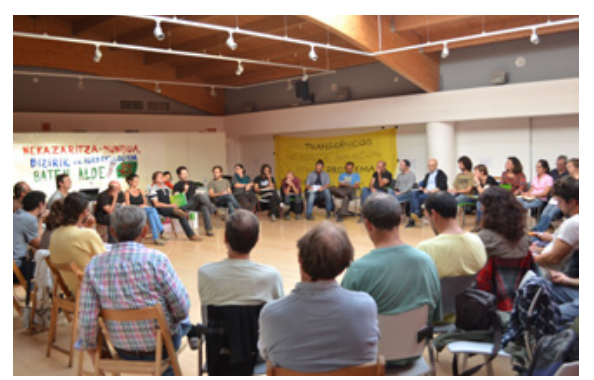

Encuentro de productores ecológicos de varias comunidades autónomas en Lizarra (Navarra) | foto Daniel López partir de las variedades agrícolas tradicionales. Esto vuelve a situar esta tradición agraria local dentro de la modernidad, como elemento de propio derecho ligado al proyecto local de desarrollo. Estos casos se dan cada vez con más frecuencia (ver al respecto, por ejemplo, LÓPEZ GARCÍA -2015-, o las experiencias ligadas al movimiento slow food, entre otros).

Con los procesos de transición agroecológica, el protagonismo de lo agrario en un medio rural desagrarizado se convierte en una actividad cargada de futuro que, lejos de estar llamada a desaparecer, puede aportar elementos valiosos para el desarrollo local. Además, es sabido que la desmotivación y desmovilización del sector agrario suponen algunos de los lastres principales para la construcción de soluciones colectivas a las problemáticas del sector. El protagonismo del manejo y conocimiento ecológico tradicionales permite que las soluciones construidas avancen hacia un manejo agrario sostenible, de manera que la propuesta agroecológica basada en la multifuncionalidad acaba por incluir al conjunto de la sociedad local. No hay que olvidar que los procesos de transición agroecológica parten del supuesto de que es preciso identificar y activar los recursos endógenos, en particular las redes de actores que puedan colaborar en un proyecto agroecológico a medio o largo plazo. Ello requiere identificar y poner a trabajar en red a agricultores ecológicos, agricultores convencionales que puedan estar interesados en cambiar de modelo, grupos de consumo organizados, escuelas y familias de alumnado que puedan exigir comedores escolares ecológicos y de proximidad, comerciantes locales, restaurantes, etc., lo cual a su vez contribuye a generar lazos territoriales $\mathrm{y}$, por tanto, a fortalecer las identidades locales alrededor de las redes alimentarias alternativas (LÓPEZ-GARCÍA; GARCÍA-GARCÍA; SAMPEDRO-ORTEGA et ál., 2019).

Existen numerosas propuestas que avanzan en esta dirección, como por ejemplo el proceso de dinamización local agroecológica que se está desarrollando en tres distritos de la ciudad de Valencia, englobadas en el proyecto "Mans a l'Horta. Dinamització de l'Activitat Agrária a l'Horta de valència", con el objetivo de revitalizar el tejido social agrario desde una perspectiva agroecológica. En este caso se ha seguido un esquema metodológico de círculos concéntricos, en el que se ha tratado de incorporar una visión de "marginalidad" de la actividad agraria periurbana (PAÜL, 2007): el círculo central se ha reservado para la creación de grupos de agricultores, con la intención de reforzar su protagonismo en los procesos. Un segundo círculo se ha construido con distintos actores sociales del distrito (principalmente asociaciones de vecinos, culturales, centros educativos, AMPAs y algunas asociaciones de comerciantes) implicados en la revitalización del tejido socioeconómico local desde una perspectiva de sostenibilidad.

En un primer momento, los agricultores han definido sus propias visiones sobre sus problemáticas (relacionadas con problemas de movilidad, seguri- 
dad en las cosechas, o degradación de las infraestructuras tradicionales de riego), así como sobre las formas de superarlas. En un segundo momento, se han construido formas y procesos de cooperación entre el primer y el segundo círculos, a partir de las prioridades planteadas por los agricultores.

En este sentido, resulta de particular interés la construcción de espacios de encuentro (foros híbridos, en la terminología de LÓPEZ-GARCÍA; CALVETMIR; DI MASSO et ál., 2018) entre ambos círculos (actores agrarios y extra-agrarios de un mismo territorio), con base en propuestas concretas de acción, que ha derivado en el refuerzo de una identidad compartida vinculada con el territorio. Esta identidad, en último término, toma cuerpo a partir de la construcción de un proyecto compartido de desarrollo alternativo y sostenible para el territorio, que incluye visiones económicas, sociales y ecológicas, y que vincula a muy distintos actores que se están viendo expulsados por el régimen alimentario corporativo (MCMICHAEL, 2016). A su vez, sin la construcción de esta nueva identidad compartida, el impulso de este nuevo modelo de desarrollo local orientado hacia la transición agroecológica no sería posible.

\section{TRANSFORMACIONES INSTITUCIONALES RELACIONADAS CON LA AGROECOLOGÍA}

Un último aspecto a considerar y discutir es el del papel de las instituciones públicas en los procesos de transición agroecológica. A pesar de que la mayor parte de los actores, en particular los protagonistas, son entidades privadas o movimientos sociales, las instituciones públicas siguen siendo las encargadas de elaborar y aplicar políticas públicas para velar y promover el bien común.

En un contexto de transición agroecológica, las instituciones públicas juegan un papel muy importante a través de, por ejemplo, programas de compra pública y de cesión de infraestructuras y recursos públicos, del apoyo para dinamizar el sector agroalimentario a escala territorial o facilitando el acceso en la tierra (bancos de tierras, reservas de suelo público para iniciativas agroecológicas, etc.), o promoviendo la recuperación de especies adaptadas a las circunstancias geoclimáticas locales, entre otras medidas. Como ya se ha comentado, existen numerosas iniciativas agroecológicas locales impulsadas o apoyadas por administraciones públicas, principalmente ayuntamientos y otros organismos locales (ver ESPLUGA; DI MASSO; LÓPEZ GARCÍA, 2019; LÓPEZ GARCÍA; FERNÁNDEZ CASADEVANTE KOIS et ál., 2017; LÓPEZ GARCÍA; ALONSO; HERRERA, 2018).

Apostar por estas estrategias requiere establecer órganos de planificación y de participación adecuados (consejos alimentarios locales, estrate-

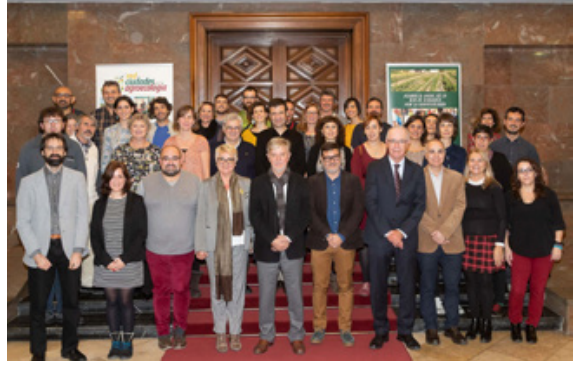

Presentación oficial de la Red de Ciudades por la Agroecología (Zaragoza, 2018) | foto Marta Álvarez (http://www.ciudadesagroecologicas.eu) 
Visita a un obrador en Tremp (Lleida), con estudiantes del Postgrado DLAE | foto Josep Espluga

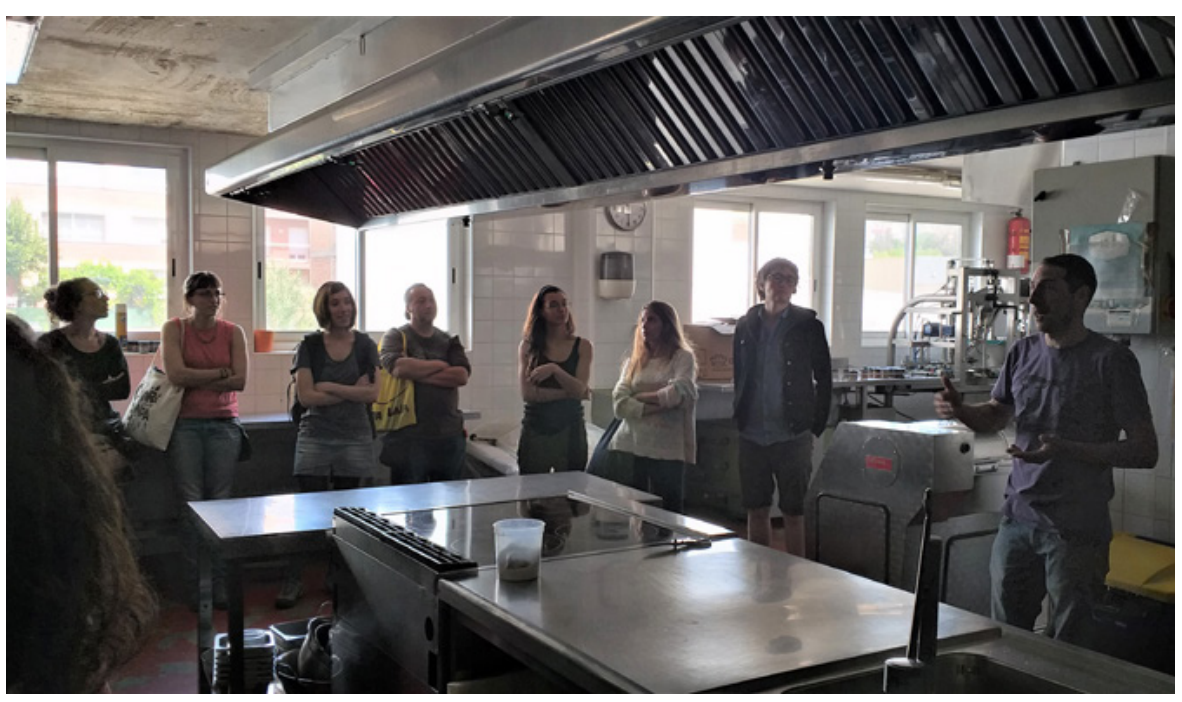

gias alimentarias, cartas municipales por la alimentación local, etc.), con el fin de facilitar diagnosis participativas, coordinar planes de acción y llevar a cabo acciones de comunicación y sensibilización pública. Por ejemplo, en el caso español, los municipios implicados en la Red de Ciudades por la Agroecología han promovido varios de estos elementos, que ya fueron recogidos y recomendados en el Pacto de Política Alimentaria Urbana de Milán del año 2015

Además de la creación de organismos o espacios colegiados de participación, como los consejos alimentarios locales y similares, en los últimos años varias administraciones públicas locales (ayuntamientos, consejos comarcales, consorcios de desarrollo local, etc.) están promoviendo un creciente número de iniciativas de dinamización agroecológica desde una óptica de soberanía alimentaria y con una fuerte dimensión territorial local.

La Dinamización Local Agroecológica (DLAE) es una estrategia de gestión dirigida a construir un sistema agroalimentario local sostenible, que permita la cohesión territorial y social, la reproducción de las comunidades locales y la conservación de los ecosistemas (véase LÓPEZ GARCÍA; TENDERO ACÍN, 2014; LÓPEZ GARCÍA; CALVET-MIR; ESPLUGA TRENC et ál., 2015; POMAR LEÓN; LÓPEZ; CALVET et ál., 2015). La lógica detrás de las iniciativas de dinamización local agroecológica es que los diferentes actores del territorio (personas productoras, consumidoras, comerciantes, etc.) deben coordinarse de manera proactiva en la consecución de un proyecto agroecológico a medio y largo plazo, y para ello es necesario contar con una figura que sea capaz de establecer vínculos entre ellas e involucrarlas en dicho proyecto compartido. La figura de la persona dinamizadora es clave para el éxito del proyecto, ya que los diferentes actores por 


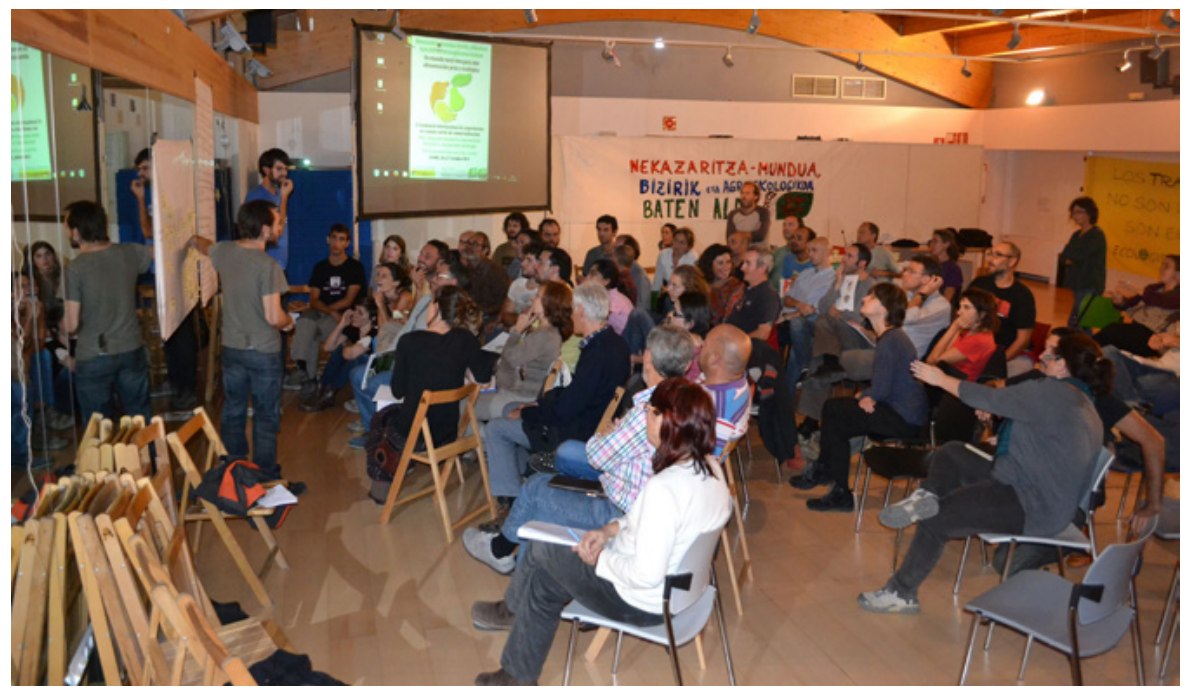

Taller participativo con agricultores ecológicos en Lizarra (Navarra) | foto Daniel López

sí solos no disponen ni del tiempo, ni los recursos, ni de la formación necesarios para poder acompañar un proceso de este tipo y mantenerlo en el tiempo.

En definitiva, los gobiernos locales están jugando un papel clave en la transición agroecológica y para ello deben dotarse de las herramientas y fórmulas organizativas adecuadas. Algo que hasta ahora es todavía incipiente, pues lo que ha predominado en una primera fase es un cierto desconcierto que se ha resuelto con mucha improvisación y creatividad. Entre los obstáculos más evidentes a día de hoy hay que mencionar la falta de integración que, de momento, estas políticas tienen con otras acciones de gobierno (ESPLUGA; DI MASSO; LÓPEZ GARCÍA, 2019). Es sabido que no es fácil coordinar políticas sectoriales diferentes, pero los promotores de las políticas alimentarias suelen formar parte de los eslabones más débiles de la administración local. Por un lado, se ubican en unidades administrativas de perfiles muy dispares (a veces son personas técnicas de desarrollo local o de promoción económica, otras son ambientólogas, otras veces son técnicas de servicios sociales, etc.); y, por otro lado, debido a su precariedad, suelen tener poca influencia sobre la toma de decisiones (con personas contratadas por proyectos, con subvenciones temporales, etc.), e impulsadas por concejales o equipos de gobierno con poca trayectoria, con lo que la continuidad de los proyectos tiende a depender demasiado de los ciclos electorales.

Por ello, el futuro de las políticas agroecológicas requeriría mayor compromiso por parte de los gobiernos municipales, una mayor solidez organizativa, así como una mayor integración territorial y la implicación de administraciones públicas de ámbitos superiores. 
El contexto socioeconómico de precariedad crónica típico de la globalización financiera y de crisis energética y ambiental hacia el que nos dirigimos es probable que contribuya a avanzar en esta dirección.

\section{A MODO DE CONCLUSIÓN}

A lo largo del texto hemos puesto de relieve los motivos por los que sería conveniente volver a situar la tierra y las actividades agrarias en el centro del debate sobre el desarrollo rural, así como la necesidad de apostar por modelos alternativos al modelo agroindustrial hegemónico, huyendo de miradas sectoriales para pasar a un enfoque de sistema agroalimentario, en el que participan actores puramente agrarios y otros que no lo son tanto pero que también habitan el territorio y con los que pueden trabajar en red.

Las propuestas agroecológicas y con perspectiva de soberanía alimentaria permiten pensar y poner en marcha procesos de transición hacia la sostenibilidad a nivel local, cuyo éxito depende de la recuperación de saberes locales y de la generación de identidades colectivas alrededor de proyectos agroecológicos. Desde esta perspectiva, por ejemplo, la recuperación de conocimiento agroecológico tradicional no consiste sólo en retomar el cultivo de ciertas variedades antiguas, sino también en movilizar todo un conocimiento colectivo vinculado al manejo y uso de dichos productos que, insertado en un proceso agroecológico de dimensión territorial, contribuirá a potenciar vínculos sociales (o capital social) y permitirá hacer emerger unas identidades colectivas indispensables para el desarrollo de los proyectos.

Todos estos procesos deberían permitir abrir espacios a alternativas hasta el momento invisibilizadas, así como avanzar hacia la sostenibilidad social y ecológica. Desde esta perspectiva, el desarrollo de una modernidad alternativa desde la agroecología, conectada con los rasgos campesinos que aún perviven en el medio rural postindustrial, aparecería como una propuesta ligada a circuitos cortos de comercialización y redes alimentarias alternativas; a nuevos manejos agrarios desde una lógica agroecológica; o a la reconstrucción de conceptos de calidad ajustados a la cultura propia y alternativos a los criterios de mercado. Como se ha mencionado, ya existen numerosas iniciativas avanzando en esta dirección, que aunque siguen siendo minoritarias presentan tendencias crecientes.

Además, el mantenimiento de dichos proyectos en el tiempo requerirá sin duda de un apoyo institucional, en forma de organismos públicos o figuras de dinamización territorial capaces de acompañar los procesos a lo largo del tiempo. De ahí que se observe la aparición de consejos alimentarios locales, de mesas de participación, de la redacción de estrategias alimentarias locales, de figuras de dinamización local agroecológica, etc. 
Hasta el momento, todo parece indicar que las instituciones más dispuestas a plantear modelos alternativos de desarrollo local y rural son los ayuntamientos y otras administraciones públicas de carácter local (diputaciones, consejos comarcales, consorcios territoriales, etc.). Quizá porque son las administraciones que tienen que lidiar con los problemas más acuciantes, en especial después de la "Gran Depresión" de 2008 y con una crisis energética y ambiental-climática en el horizonte que puede poner en crisis el sistema agroalimentario hegemónico. En este sentido, la recuperación y promoción, o incluso reinvención, de un patrimonio cultural local juega un papel estratégico para avanzar hacia un desarrollo rural más sostenible, tanto desde el punto de vista socioeconómico como ambiental. 


\section{BIBLIOGRAFÍA}

- AltieRI, M. A. (1987) Agroecology. The Scientific Basis of Alternative Agriculture. Boulder: Wetsview Press, 1987

- BELL, M.M., LLOYD, S. E.; VAVOTEC, C. (2010) Activating the Countryside: Rural Power, the Power of the Rural and the Making of Rural Politics. Sociologia Ruralis, vol. 50, n. ${ }^{\circ}$ 3, 2010, pp. 205-224 <https://doi. org/10.1111/j.1467-9523.2010.00512> [Consulta: 06/09/20 19]

- BERKES, F. (1993) Traditional Ecological Knowledge in perspective. En INGLIS, J. T. (ed.) Traditional Ecological Knowledge: Concepts and Cases. Ottawa, Canada: The International Development Research Centre (IDRC), 1993 pp. 1-6

- CALVET-MIR, L. (2019) Conocimiento Ecológico Tradicional (Tema 3.2. Materiales docentes del Postgrado de Dinamización Local Agroecológica). Bellaterra: Universitat Autònoma de Barcelona, 2019

- CALVET-MIR, L.; CALVET-MIR, M.; REYES-GARCÍA, V. (2010) Traditional ecological knowledge and landraces in situ conservation in high mountain home gardens of Vall Fosca, Catalan Pyrenees, Iberian Peninsula. En POCHETTINO, M. L.; LADIOAND A. H. P.; ARENAS, M. (ed.) Tradiciones y transformaciones en etnobotánica. Argentina: CYTED, 2010, pp. 457-464

- CALVET-MIR, L.; BENYEI, P.; ACEITUNO-MATA, L.; PARDO-DE-SANTAYANA,M.; LÓPEZ-GARCÍA, D.; CARRASCOSA-GARCÍA, M.; PERDOMO-MOLINA, A.; REYES-GARCÍA, V. (2018) The Contribution of Traditional Agroecological Knowledge as a Digital Commons to Agroecological Transitions: The Case of the CONECT-e Platform. Sustainability, vol. 10, n. ${ }^{\circ}$ 9, 2018 <https://doi. org/10.3390/su10093214> [Consulta: 29/08/2019]

- CINNER, J.; MARNANE, M. J.; MCCLANAHAN, T. R.; ALMANY, G. R. (2005) Periodic closures as adaptive coral reef management in the Indo-Pacific. Ecology and Society [en línea], vol. 11, n. ${ }^{\circ} 1,2005<$ http://www.ecologyandsociety. org/vol11/iss1/art31/> [Consulta: 29/08/2019]

- CleMENTE, J; LÓPEZ-GARCÍA, D.; DIMASSO, M; GARCÍA GARCÍA, V. (2019) Feminismo y agroecología: puentes y brechas en torno a las políticas alimentarias urbanas. Comunicación inédita presentada al VI Congrés d'Economía Feminista, València, 5-7 de septiembre de 2019

- DANIEL, J. F. (2011) Action Research and Performativity: How Sociology Shaped a Farmers' Movement in The Netherlands. Sociologia Ruralis, vol. 51, n. ${ }^{0} 1,2011$, pp.17-34 <https://doi.org/10.1111/j.1467-9523.2010.00525.x> [Con sulta: 02/10/2019]

- DI MASSO, M. (2013) Redes alimentarias alternativas y soberanía alimentaria. Posibilidades para la transformación del sistema agroalimentario dominante. Tesis doctoral.
Departamento de Sociología, Universitat Autònoma de Barcelona, 2013 <https://ddd.uab.cat/record/114317> [Consulta: 05/09/2019]

- DIAMOND, J. (2005) Collapse: How societies choose to fail or succeed. New York: Viking Press, 2005

- DIRKSMEIER, P.; HELBRECHT, I. (2008) Time, nonrepresentational theory and the 'performative turn'towards a new methodology in qualitative social research. Forum Qualitative Sozialforschung/Forum Qualitative Social Research [en línea], vol. 9, n. 2, 2008, pp.1-15 <http://www.qualitative-research.net/index.php/fqs/article/ view/385/839> [Consulta: 29/08/2019]

- ESPlugA, J. (2002) Percepción del riesgo y uso de pesticidas en la agricultura. Ecología Política, Cuadernos de Debate Internacional, vol. 22, 2002, pp. 17-30

- ESPLUGA, J. (2004) La exposición laboral a pesticidas en la agricultura. Un caso de aparente subestimación del riesgo. Sociología del Trabajo, vol. 51, 2004, pp. 33-60

- ESPlUGA, J.; DI MASSO, M.; LÓPEZ GARCíA, D. (2019) Agroecologia i polítiques per la sobirania alimentària: fórmules per afrontar la triple crisi energètica, ambiental i econòmica. En GOMÀ, R.; SUBIRATS, J. (ed.) Canvi d'època $i$ de polítiques publiques a Catalunya. Barcelona: Galaxia Guttenberg, 2019, pp. 144-159

- ESTRATEGIA de Alimentación Sostenible y Saludable (2019)[en línea].Zaragoza:Ayuntamiento de Zaragoza, 2019 <https://www.zaragoza.es/contenidos/medioambiente/ alimentacion/EASS_Zaragoza_Mayo2019_definitivo.pdf > [Consulta: 06/09/2019]

- EYSSARTIER, C.; LADIO, A. H.; LOZADA, M. (2011) Horticultural and Gathering Practices Complement Each Other: A Case Study in a Rural Population of Northwestern Patagonia. Ecology of Food and Nutrition, vol. 50, n. ${ }^{\circ} 5$, 2011, pp. 429-451

- FRANCIS, C.; LIEBLEIN, G.; GLIESSMANS.; BRELAND, T. A.; CREAMER, N.; HARWOOD, R.; SALOMONSSON, L.; HELENIUS, J.; RICKERT, D.; SALVADOR, R.; WIEDENHOEFT, M.; SIMMONS, S.; ALLEN, P.; ALTIERI, M.; FLORA, C.; POINCELOT, R. (2003) Agroecology: The Ecology of Food Systems. Journal of Sustainable Agriculture, vol. 22, n. ${ }^{\circ} 3,2003$, pp. 99-118

- GALLAR HERNÁNDEZ, D. (2011) La construcción de la Universidad Rural Paulo Freire. Culturalismo para una nueva ruralidad campesinista. Córdoba: Universidad de Córdoba, Servicio de Publicaciones, 2011 (Colección Tesis Doctorales UCO)

- GARRIDO FERNÁNDEZ, F. E. (1999) Análisis de los discursos, actitudes y estrategias de los agricultores y sus organizaciones profesionales ante la introducción de métodos de desarrollo sostenible en la agricultura europea. 
Tesis doctoral inédita Departamento de Economía, Sociología y Políticas Agrarias, U. de Córdoba, 1999

- GliessmaN, S. R. (1997) Agroecology. Ecological Processes in Sustainable Agriculture. Chelsea: Ann Arbor Press, 1997

- GÓMEZ-BAGGETHUN, E.; MINGORRÍA, S.; REYESGARCÍA, V.; CALVET-MIR, L.; MONTES, C. (2010) Traditional Ecological Knowledge Trends in the Transition to a Market Economy: Empirical Study in the Doñana Natural Areas. Conservation Biology, vol. 24, n. ${ }^{\circ} 3,2010$, pp. 721-729

- GÓMEZ-BAGGETHUN, E.; REYES-GARCÍA, V. (2013) Reinterpreting change in traditional ecological knowledge. Human Ecology, vol. 41, n. ${ }^{\circ} 4,2013$, pp. 643-647

- GONZÁLEZ DE MOLINA, M. (ed.) (2009) El desarrollo de la agricultura ecológica en Andalucía (2004-2007). Crónica de una experiencia agroecológica. Barcelona: Icària, 2009

- GONZÁLEZ DE MOLINA, M. (2013) Agroecology and Politics. How To Get Sustainability? About the Necessity for a Political Agroecology. Agroecology and Sustainable Food Systems, vol. 37, n. ${ }^{\circ} 1,2013$, pp. 45-59

- GUZMÁN CASADO, G. I.; GONZÁLEZ DE MOLINA, M.; SEVILLA GUZMÁN, E. (2000) Introducción a la Agroecología como desarrollo rural sostenible. Madrid: Mundi-Prensa, 2000

- HENRICH, J. (2004) Demography and cultural evolution: How adaptive cultural processes can produce maladaptive losses-The Tasmanian case. American Antiquity, vol. 69, n. ${ }^{\circ} 2,2004$, pp. $197-214$

- LOCKIE, S. (1997) Chemical Risk and the SelfCalculating Farmer: Diffuse Chemical Use in Australian Broadacre Farming Systems. Current Sociology, vol. 45, n. ${ }^{\circ} 3,1997$, pp. 81-97

- LÓPEZ GARCíA, D. (2011) Canales cortos de comercialización como elemento dinamizador de las agriculturas ecológicas urbana y periurbana. En Actas del I Congreso Estatal de Agricultura Ecológica Urbana y Periurbana. Elx: SEAE-UMH-Ajuntament d'Elx, 2011

- LÓPEZ GARCÍA, D. (2015) Producir alimentos, reproducir comunidad. Redes alimentarias alternativas como formas económicas para la transformación social y ecológica. Madrid: Libros en Acción, 2015

- LÓPEZ GARCÍA, D.; GUZMÁN CASADO, G. I. (2013) Si la tierra tiene sazón... El conocimiento tradicional campesino como movilizador de procesos de transición agroecológica. Agroecología, vol. 7, n. ${ }^{\circ} 2,2013$, pp. 7-20

- LÓPEZ GARCÍA, D.; CALVET-MIR, L.; ESPLUGA TRENC, J.; DI MASSO TARDITTI, M.; TENDERO ACÍN, G.; POMAR LEÓN, A. (2015) La dinamización local agroecológica como estrategia para la construcción de soberanías locales. Ecología Política, n. ${ }^{\circ} 49,2015$, pp. $28-$ 34

- LÓPEZ GARCÍA, D.; FERNÁNDEZ CASADEVANTE KOIS, J. L.; MORÁN, N.; OTEROS ROZAS, E. (ed.) (2017) Arraigar las instituciones. Propuestas de políticas agroecológicas desde los movimientos sociales. Madrid: Libros en Acción, 2017

- LÓPEZ GARCÍA, D.; ALONSO, N.; HERRERA, P. M. (2018) Políticas alimentarias urbanas para la sostenibilidad. Análisis de experiencias en el Estado español, en un contexto internacional. Valladolid: Fundación Entretantos, 2018. Disponible en <http://www. ciudadesagroecologicas.eu/wp-content/uploads/2018/04/ PoliticasAlimentariasUrbanas ParaLaSostenibilidad Informe_v4.pdf> [Consulta: 29/08/2019]

- LÓPEZ-GARCÍA, D.; CALVET-MIR, L.; DI MASSO, M.; ESPLUGA, J. (2018) Multi-actor networks and innovation niches: university training for local Agroecological Dynamization. Agriculture and Human Values, vol. 36, n. ${ }^{\circ}$ 3, 2018, pp. 567-579 <https://doi.org/10.1007/s10460-0189863-7> [Consulta: 29/08/2019]

- LÓPEZ GARCÍA, D.; GARCÍA GARCÍA, V.; SAMPEDRO GARCÍA, Y.; POMAR LEÓN, A.; TENDERO ACÍN, G.; SASTRE MORATÓ, A.; CORRERO-HUMANES, A. (2019) Exploring the Contradictions of Scaling: Action Plans for Agroecological Transition in Metropolitan Environments. Agroecology and Sustainable Food Systems <https://doi.or g/10.1080/21683565.2019.1649783>

- MARULL, J. (dir.) DOMENE, E. (coord.); GARCÍA, M.; CAÑAS, C.; CATTANEO, C.; COLL, F.; QUERALT, E. (2016) Agricultura Metropolitana. Agricultura urbana i periurbana a l'àmbit metropolità de Barcelona: beneficis econòmics, socials i ambientals. Barcelona: Área Metropolitana de Barcelona, Institut d'Estudis Regionals i Metropolitans de Barcelona (IERMB), 2016 <https://iermb.uab.cat/wpcontent/uploads/2017/02/16026.pdf> [Consulta: 04/09/20 17]

- McMiCHAEL, P. (2016) Regímenes alimentarios y cuestiones agrarias. Barcelona: Icaria, 2016

- MOLLER, H.; BERKES, F.; LYVER, O.; KISLALIOGLU, M. (2004) Combining Science and Traditional Ecological Knowledge: Monitoring Populations for Co-Management. Ecology and Society [en línea], vol. 9, n. ${ }^{\circ} 3,2004<$ http:// www.ecologyandsociety.org/vol9/iss3/art2/>

- PAÜL, V. (2007) Agricultural marginality and marginal agriculture in metropolitan areas. A proposal for systematisation based on some spanish case-studies". En JONES, G.; LEIMGRUBER, W.; NEL, E. Issues on geographical marginality. Grahamstown, South Africa: Rhodes University, 2007 
- PLOEG, J. D. (2010) Nuevos campesinos. Campesinos e imperios alimentarios. Barcelona: Icaria Editorial, 2010

- pomar leÓN, A.; LÓPEZ, D.; CALVET, L.; ESPLUGA TRENC, J.; DI MASSO, M.; TENDERO, G. (2016) Dinamización Local Agroecológica: la participación como estrategia para la sostenibilidad de las comunidades agrarias. Boletín Carpeta Informativa del CENEAM, enero de 2016. Disponible en <https://www.miteco.gob.es/es/ ceneam/articulos-de-opinion/2016-01-ariadnapomar tcm30-163507.pdf> [Consulta: 29/08/2019]

- PURI, R. K. (2005) Deadly dances in the Bornean rainforest: Hunting knowledge of the Penan Benalui. Leiden: KITLV Press, 2005

- REED, M. (2008) The rural arena: the diversity of protest in rural England. Journal of Rural Studies, vol. 24, n. ${ }^{\circ} 2$, 2008, pp. 209-218

- REYES-GARCÍA, V. (2009) Conocimiento ecológico tradicional para la conservación: Dinámicas y conflictos. Papeles de relaciones ecosociales y cambio global, n. ${ }^{\circ}$ 107, 2009, pp. 39-55

- REYES-GARCÍA, V. (2015) The Values of Traditional Ecological Knowledge. En MARTÍNEZ-ALIER, J.; MURADIAN, R. (ed.) Handbook of Ecological Economics. Cheltenham: Edward Elgar Publishing, 2015, pp. 283$306<$ <ttps://doi.org/10.4337/9781783471416.00016> [Consulta: 02/10/2019]

- REYES-GARCÍA V.; ACEITUNO-MATA, L.; CALVETMIR, L.; GARNATJE, T.; GÓMEZ-BAGGETHUN, E.; LASTRA, J. J.; ONTILLERA, R.; PARADA, M.; PARDO-DESANTAYANA, M.; RIGAT, M.; VALLĖS, J.; VILA, S. (2014) Resilience of local knowledge systems. The example of agricultural knowledge among home gardeners in the Iberian peninsula. Global Environmental Change, n. ${ }^{\circ} 24$, 2014, pp. 223-231

- RIU-BOSOMS, C. (2012) El coneixement ecològic local en la gestió dels horts: Com es transmet? Un cas d'estudi entre els hortolans de la vall de Gósol. Pirineu Català. Península Ibèrica. Tesis de Màster (inédita). Universitat Autònoma de Barcelona, 2012

- SMITH A., WISHNIE M. (2000) Conservation and subsistence in small-scale societies. Annual Review of Anthropology, n. ${ }^{\circ} 29,2000$, pp. 493-524

- SOBERANÍA alimentaria: un futuro sin hambre (1996) Declaración de La Vía Campesina la Cumbre Mundial sobre Seguridad Alimentaría y en el Forum de Organizaciones No Gubernamentales en noviembre de 1996, en Roma

- TOledo, V. (2002) Ethnoecology: a conceptual framework for the study of indigenous knowledge of nature. En 7th, International congress of ethnobiology; Ethnobiology and biocultural diversity; 2000; Athens, GA. Georgia, USA: International Society of Ethnobiology, 2002, pp. 511-522 
